\title{
Prevenção e erradicação do trabalho infantil: mediações e comunicação pública
}

\author{
Prevention and eradication of child labor: \\ mediation and public communication
}

Prevención y erradicación del trabajo infantil: mediaciones y comunicación pública

Luíza Mônica Assis Silva

- Doutora em Psicologia Social, do Trabalho e das Organizações pela Universidade de Brasília (UnB)

- Mestre e graduada em Ciência Política pela UnB

- Graduada em Jornalismo pelo Centro de Ensino Unificado de Brasília (Ceub)

- Professora do Mestrado em Comunicação da Universidade Católica de Brasília (UCB), linha de pesquisa Processos Comunicacionais nas Organizações

- Professora da graduação nos cursos de Jornalismo e Publicidade da UCB.

- E-mail: luiza@ucb.br

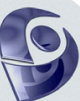

Daniella Rocha Magalhães

- Mestre em Comunicação pela Universidade Católica de Brasília (UCB)

- Graduada em Jornalismo pela Universidade Federal de Goiás (UFG)

- Especialista em Democracia, Participação e Movimentos Sociais pela Universidade Federal de Minas Gerais UFMG

- Consultora na área de direitos humanos

- E-mail: rochamdani@gmail.com 


\section{Resumo}

Tivemos como objetivo compreender a natureza da comunicação realizada pelo Fórum Nacional de Prevenção e Erradicação do Trabalho Infantil (FNPETI) como instância de mediação. Buscamos articular os saberes do campo organizacional, das instituições da sociedade civil, com as abordagens dos estudos de recepção (Martín-Barbero, 1995, 2008, 2009) e da comunicação pública (Mainiere, 2016; López, 2011; Matos, 2011; Duarte, 2009). A metodologia foi qualitativa, realizando-se análise documental de texto institucional, entrevista semiestruturada e observação nãoparticipante. As categorias analíticas foram a institucionalidade e a relação comunicação/cultura/política. Avaliamos que o FNPETI, por ter como função articular atores em torno do interesse público, configura-se como ator de mediação da área infantojuvenil, tendo na comunicação pública sua principal referência.

\section{PALAVRAS CHAVE: COMUNICAÇÃO • COMUNICAÇÃO PÚBLICA•ORGANIZAÇÕES DA SOCIEDADE CIVIL・ESTUDOS DE RECEPÇÃO.}

\section{Abstract}

The purpose of our work was to understand the nature of the communication established by the National Forum for the Prevention and Eradication of Child Labor (Fórum Nacional de Prevenção e Erradicação do Trabalho Infantil - FNPETI) as a mediation panel. We saught to consider the knowledge of the organizational field, of the civil society institutions, with the approaches of reception studies (Martín-Barbero, 1995, 2008, 2009) and of public communication (Mainiere, 2016; López, 2011; Matos, 2011; Duarte, 2009). The qualitative methodology was applied, carrying out documentary analysis of institutional text, semi-structured interview and non-participant observation. The analytical categories were institutionality and the communication/culture/politics relation. Our consideration was that the FNPETI, which function is to develop players towards the public interest, is a mediating factor in the child and youth area, having public communication as its main reference.

\section{KEYWORDS: COMMUNICATION • PUBLIC COMMUNICATION・CIVIL SOCIETY ORGANIZATIONS・RECEPTION STUDIES.}

\section{Resumen}

Tuvimos como objetivo comprender la naturaleza de la comunicación realizada por el Foro Nacional de Prevención y Erradicación del Trabajo Infantil (Fórum Nacional de Prevenção e Erradicação do Trabalho Infantil - FNPETI) como instancia de mediación, en la categoría institucionalizada. Buscamos articular los saberes en el campo organizacional de las instituciones de la sociedad civil con los enfoques de los estudios de recepción (Martín-Barbero, 1995, 2008, 2009) y de la comunicación pública (Mainiere, 2016; López, 2011; Matos, 2011; Duarte, 2009). La metodología fue cualitativa, realizándose análisis documental de texto institucional, entrevista semi estructurada y observación no participante. Estimamos que el FNPETI, por tener como función articular actores en torno al interés público, se configura como factor de mediación del área infantojuvenil, teniendo en la comunicación pública su principal referencia. 


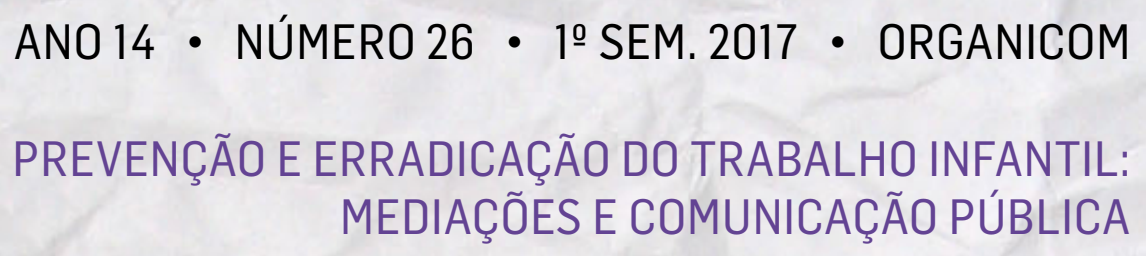

A s organizações da sociedade civil da área da infância e adolescência que atuam com o tema do enfrentamento ao trabalho infantil' exercem importante papel no monitoramento e na qualificação das políticas públicas relativas ao tema. Além disso, buscam cumprir o desafio de desnaturalizar o trabalho infantil como algo aceitável e de desconstruir seu sentido positivo como, geralmente, o fenômeno é percebido no senso comum.

Uma dessas organizações é o Fórum Nacional de Prevenção e Erradicação do Trabalho Infantil (FNPETI), uma articulação nacional que reúne atores estratégicos ligados à sociedade civil, empregadores e trabalhadores, além do governo federal, organismos internacionais e sistema de Justiça. Apesar do seu caráter híbrido, congregando atores dos campos social e público, o FNPETI é uma organização da sociedade civil, sem qualquer vinculação governamental, seja em nível institucional ou financeiro.

Entre as ações prioritárias do fórum, uma é sensibilizar e mobilizar a sociedade, por meio de campanhas anuais de mobilização social sobre o tema. Isso porque, mesmo com a redução no percentual de meninas e meninos trabalhadores no Brasil ao longo de vinte anos (Pnad, 2014), o fenômeno ainda persiste como algo natural ou necessário, sobretudo para crianças e adolescentes de baixa renda, e não como violação de direitos, como determinam as normativas nacionais e internacionais.

Ao realizar pesquisa sobre o tema, entre 2015 e 2016, buscamos compreender a construção de sentidos sobre trabalho infantil a partir das campanhas veiculadas, investigando o polo de produção, representado pelo fórum, e o polo de recepção, representado por um grupo de adolescentes beneficiários das políticas públicas de enfrentamento ao trabalho infantil no Distrito Federal.

No polo de produção optamos por trabalhar com o campo teórico-metodológico dos estudos de recepção, tendo como referência Jesús Martín-Barbero (1995, 2008, 2009), utilizando como categorias de análise a institucionalidade, presente no mapa das mediações elaborado pelo autor e a relação comunicação/cultura/política. Além disso, apresentamos alguns aportes sobre comunicação pública (Mainiere, 2016; López, 2011; Matos, 2011; Duarte, 2009), partindo do entendimento de que o FNPETI é uma organização social de interesse público, que atua com um tema também de interesse público.

Partimos do entendimento de que, para avaliar a função de mobilização social do FNPETI, antes é preciso compreender como essa organização atua comunicacionalmente. Nosso pressuposto é de que o conceito que confere à comunicação se refletirá na forma como ela é pensada e apropriada pela organização em suas ações mobilizadoras, sobretudo nas campanhas. Assim, nosso objetivo foi compreender de que forma o FNPETI se estrutura como uma organização de mediação, que produz comunicação pública.

\section{ESTUDOS DE RECEPÇÃO E COMUNICAÇÃO PÚBLICA SOB A ÓTICA DAS ORGANIZAÇÕES E MOVIMENTOS SOCIAIS}

A proposta de Jesús Martín-Barbero (2008), nos estudos de recepção, é de deslocar o olhar dos meios para as mediações, tendo como focos centrais a cultura, as mediações e os sujeitos, a partir de suas práticas comunicativas e de suas condições

1 A Constituição Federal define trabalho infantil como toda atividade econômica e/ou de sobrevivência, com ou sem finalidade de lucro e remuneração, executada por crianças e adolescentes menores de 16 anos - o que é proibido. Acima de 14 anos, as/os adolescentes de ambos os sexos podem ser admitidos no emprego somente na condição de aprendizes, desde que em funções que não ofereçam risco à sua saúde, segurança e integridade física e mental. É proibido ainda o trabalho ou emprego noturno, perigoso e insalubre para adolescentes que não completaram 18 anos. As legislações que normatizam o trabalho infantil no Brasil são: Convenção 138, da Organização Internacional do Trabalho (OIT), adotada a partir de 1973 e ratificada pelo Brasil em 2002 e que trata da idade mínima para o trabalho; artigo $7^{\circ}$, inciso XXXIII, da Constituição Federal; artigo 405, da Consolidação das Leis do Trabalho (CLT); artigo 67, do Estatuto da Criança e do Adolescente, e Lei10.097/2000, decreto 5.598/2005, que trata da aprendizagem. 
ANO 14 • NÚMERO 26 • 1ํㅗ․ 2017 • ORGANICOM

PREVENÇÃO E ERRADICAÇÃO DO TRABALHO INFANTIL: MEDIAÇÕES E COMUNICAÇÃO PÚBLICA

sociais. Os meios, suas instituições e a mídia massiva passam a ser analisados pelo olhar dos movimentos sociais, de suas práticas cotidianas e de suas matrizes culturais, como elementos para a produção, negociação e disputa de sentidos.

0 pesquisador estrutura um mapa das mediações como forma de teorizar e esquematizar as relações entre comunicação e cultura. 0 mapa passou ao longo dos anos por várias modificações, com base nas análises do autor quanto ao impacto das tecnologias na comunicação e na cultura. Particularmente, nos interessa uma das mediações constantes no mapa (presente na quinta edição do livro Dos meios às mediações, 2008), a institucionalidade, por ter maior aderência à análise institucional e comunicacional do FNPETI.

A institucionalidade refere-se à produção e regulação dos discursos públicos que, de forma negocial ou contraposta, fazem o Estado e a sociedade. Enquanto o Estado busca, nesse discurso, a estabilidade da ordem instituída, os cidadãos (maiorias e minorias) buscam defender seus direitos e fazer-se reconhecer. Trata-se dos meios e das formas de construção de discursos e práticas por meio das diferentes linguagens midiáticas.

Martín-Barbero (2008) aponta a assimetria de forças da institucionalidade, com a maior produção de discursos voltada a atender aos interesses e lógicas privados. Por outro lado, reconhece que há uma multiplicação de movimentos em busca de outras institucionalidades que não aquelas clássicas mantidas pelos partidos tradicionais e as instituições públicas - e aqui incluiríamos também as privadas - no sentido de disputar outros sentidos para a cidadania e deslocá-la para o âmbito cultural, o mesmo ocorrendo no plano da representação para o do reconhecimento instituinte.

Em uma sociedade cada vez mais midiatizada e tecnológica, Martín-Barbero (2008, p. 12) nos chama a atenção sobre o quanto a comunicação se tornou estruturante da vida contemporânea, exigindo de nós um esforço contínuo para compreender "a cada dia mais complexa trama de mediações que a relação comunicação/cultura/política articula".

Do lado da comunicação, o autor argumenta sobre a necessidade de pensarmos no lugar estratégico que ela passou a ocupar na configuração dos novos modelos de sociedade (globalizada, mediatizada, mercadológica); do lado da cultura, sua compreensão como intrínseca da vida social por inteiro, sendo tanto sujeito quanto objeto de cultura, a arte, a saúde, o trabalho, a violência, bem como a cultura política, organizacional, tecnológica, de gênero, geração, entre outras. Do lado da política, as mediações que constituem novos modos de interpelação dos sujeitos e de representação dos vínculos que dão coesão à sociedade. As mediações, mediatizadas ou não, passaram a fazer parte da trama dos discursos e da própria ação política.

As mediações e as articulações de organizações como o FNPETI, nesse cenário, estão continuamente perpassadas pela comunicação, cultura e política. 0 autor indica a necessidade de reconhecimento das experiências coletivas dos novos sujeitos políticos, não enquadradas nas formas partidárias e que introduzem outros sentidos ao social, bem como novos usos sociais aos meios. Segundo ele, são atores e movimentos emergentes que atuam como mediadores socioculturais, buscando, entre tensões, constituir "novas maneiras de estar juntos pelas quais se recria a cidadania e se reconstitui a sociedade" (Martín-Barbero, 2008, p. 21).

A comunicação pública, segundo López (2011), pode ser cumprida com duas condições: que resulte de sujeitos coletivos, ainda que representados ou de sua expressão por meio de indivíduos; e que esteja referida à construção do que é público.

O foco no sujeito, com base no diálogo e na interação, é o cerne da definição oferecida por Mainiere (2016) para o conceito. Para ele, a comunicação pública 
abarca a comunicação entre Estado, governo e sociedade, cujo locus é a esfera pública. Manifestando-se enquanto um espaço de interlocução e de intervenção do cidadão no debate de questões de interesse público, a comunicação pública assume uma dimensão cidadã (Mainiere, 2016, p. 75).

Matos (2011) compartilha essa definição e agrega a ela o conceito de participação, ou seja, de que mais do que ser receptora de informações transparentes e contextualizadas (uma das condições da comunicação pública), a sociedade pode ser também produtora, construindo, disputando e circulando sentidos acerca dos temas de interesse público. A autora engloba como atores na comunicação pública entes diversificados, tais como a mídia, o mercado, as universidades, as instituições religiosas, a sociedade "e os segmentos a que se tem negado reconhecimento - estejam eles vinculados ou não a instituições ou associações formais" (Matos, 2011, p. 45).

\section{O FNPETI}

O Fórum Nacional de Prevenção e Erradicação do Trabalho Infantil (FNPETI) é uma organização da sociedade civil que pode ser tipificada como de articulação e mediação política, conforme classificação de Scherer-Warren (2006), porém de caráter híbrido, envolvendo a participação do poder público na sua composição.

Criada em 1994, a organização caracteriza-se como uma articulação envolvendo o Estado brasileiro de forma ampla nas definições da política pública para a prevenção e erradicação do trabalho infantil. Agrega representantes do governo federal, dos trabalhadores, dos empregadores, de entidades da sociedade civil, do sistema de Justiça e de organismos internacionais. Além disso, é composto por 27 fóruns estaduais, com formato semelhante ao nacional, que trabalham no formato de rede. Não há registro de outra organização nesse formato no país.

A secretaria executiva do fórum é bastante enxuta, contando apenas com duas pessoas profissionalizadas: uma secretáriaexecutiva e uma assistente administrativa. Eventualmente, há contratação de consultorias para a realização de pesquisas ou de atividades comunicacionais. De resto, todas as ações e estratégias são executadas de forma voluntária pelos membros pessoas físicas ou por representantes de outras organizações participantes.

Trata-se de uma organização de organizações, que tem como fio condutor um tema - o trabalho infantil - e cujas estrutura, funções, atribuições e papéis são distribuídos pelos membros participantes, sem setores ou departamentos, substituídos pelas ações executadas, no cotidiano, pelos próprios participantes. No caso da comunicação, nosso objeto de análise, ela está inserida nessa mesma dinâmica organizacional, não sendo possível, portanto, uma definição também clássica da sua estrutura, com profissionais, funções e áreas específicas.

\section{METODOLOGIA}

O estudo teve caráter qualitativo, utilizando uma abordagem plurimetodológica - entrevista, análise documental e observação não participante. A análise documental teve como corpus texto institucional do FNPETI contendo seus objetivos, estrutura e formato, disponível no site institucional ${ }^{2}$. Foi realizada ainda observação não participante de três reuniões anuais da assembleia de associados, ocorridas em 2015, que tiveram como objetivos decidir sobre as

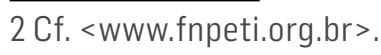


ANO 14 • NÚMERO 26 • 1은. 2017 • ORGANICOM

PREVENÇÃO E ERRADICAÇÃO DO TRABALHO INFANTIL: MEDIAÇÕES E COMUNICAÇÃO PÚBLICA

campanhas de mobilização, os posicionamentos políticos e as estratégias de advocacy. Também foi realizada entrevista semiestruturada com a secretária executiva da organização. As categorias teóricas de análise utilizadas para análise do corpus foram a institucionalidade e a relação comunicação/cultura/política, conforme aportes de Martín-Barbero (2008).

Todo o corpus (documento institucional, entrevista e anotações registradas num diário de campo) foi analisado à luz dos estudos de recepção e da abordagem sobre comunicação pública. Para o texto institucional utilizamos as seguintes etapas analíticas, baseadas no método proposto por Bardin (2011): pré-análise, com leitura flutuante do texto institucional e demarcação do universo textual a ser analisado; exploração semiaberta do material; tratamento, interpretação e análise dos dados. As anotações do diário e a entrevista foram relacionadas às categorias teóricas.

\section{RESULTADOS E DISCUSSÃO}

Martín-Barbero (2008) argumenta que a institucionalidade é uma mediação densa de interesses e poderes contrapostos, que afeta a regulação dos discursos. Vista a partir da comunicação, a institucionalidade é uma questão de meios, ou seja, de produção de discursos públicos.

Numa organização da natureza do FNPETI, que agrega atores sociais e públicos num mesmo espaço, essa mediação de interesses e poderes fica bem evidente. Segundo a secretária-executiva da organização, este é o principal ponto de tensão e, por vezes, de desagregação, e que pode se dar tanto entre sociedade civil e governo, quanto internamente entre os segmentos sociais. E, como afirma Martín-Barbero, afeta a regulação de discursos públicos.

Tomemos um exemplo. Em novembro de 2015, a Pesquisa Nacional por Amostra de Domicílios (Pnad/IBGE) divulgou um estudo apontand o que em 2014 houve uma alta de 9,48\% nos índices de trabalho infantil no país em relação ao ano anterior (2013), representando a primeira elevação depois de uma década de declínio nos índices. Os dados ganharam repercussão pública, sobretudo na mídia de massa ${ }^{3}$, com discursos tensionados entre governo e sociedade civil, mostrando como cada um regulou suas falas e que elas não foram consensuais.

Enquanto a ex-ministra do então Ministério do Desenvolvimento Social e Combate à Fome (MDS), Tereza Campelo, afirmava que a situação era uma "flutuação" temporária e fora da curva nos índices, a secretaria executiva do FNPETI classificava o número como uma "tragédia" e falta de cuidado do poder público na proteção das crianças e dos adolescentes. Essa polarização foi exposta, publicamente, na cobertura de alguns veículos e se deu entre atores de diferentes campos que atuam conjuntamente num mesmo espaço político, o FNPETI.

Situações como essa fazem parte do cotidiano do fórum e explicitam a densidade e tensão que a institucionalidade tem nessa organização. Também nos mostra o quanto comunicação, cultura e política estão imbricadas naquele espaço.

A regulação dos discursos ocorre ainda no âmbito interno e é marcada por intensa produção discursiva e negociações. As reuniões de assembleia são o momento presencial mais importante do fórum, quando ele discute e delibera sobre os assuntos considerados prioritários para a organização e sobre seus posicionamentos públicos.

3 A pesquisa sobre a divulgação dos dados do IBGE foi feita em base eletrônica e incluiu os seguintes veículos: G1, Fundação Telefônica/Promenino, Valor Econômico e Folha de S.Paulo. 
Numa dessas reuniões, em setembro de 2015, os associados discutiram se acatavam ou não a filiação de quatro organizações da sociedade civil, que haviam solicitado seu ingresso alguns meses antes e que nomeamos pelas letras $A, B, C$ e D. Abaixo resumimos, brevemente, o conteúdo das conversações, caracterizando as falas pelos segmentos que representam no FNPETI:

- Secretaria executiva: afirma que a organização A conta com financiamento de uma empresa fumageira que possui, comprovadamente, trabalho infantil na sua produção, inclusive já tendo assinado Termo de Ajustamento de Conduta (TAC) com o Ministério Público do Rio Grande do Sul. Manifesta receio em sua filiação, pois o fórum definiu como norma não fazer parcerias com organizações ou indivíduos que tenham ligação com trabalho infantil.

- Segmento empregador: argumenta que o FNPETI precisa ter critérios mais objetivos e menos subjetivos para definir as aprovações. Afirma ter entrado no site da organização A e visto que executam vários projetos importantes, inclusive com o tema do trabalho infantil na área rural no sul do país, onde a situação é grave e complexa. Salienta que quem pediu a filiação foi a organização e não seus financiadores e sugere como critério que toda organização que quiser se filiar participe antes de uma reunião presencial para se apresentar e justificar seu pedido.

- Segmento organizações da sociedade civil: afirma desconhecer o trabalho da organização A, pois nunca passou pelo Conselho Estadual dos Direitos da Criança e do Adolescente do Rio Grande do Sul, e solicita conhecê-la primeiro, para então tomar uma decisão.

- Segmento fóruns estaduais: sugere que todos os pedidos de filiação ao fórum nacional só ocorram após parecer dos fóruns estaduais.

- Secretaria executiva: coloca na pauta a organização B, afirmando que tem trabalhos importantes, mas é mantida por uma grande empresa do ramo de entretenimento, que atua com trabalho infantil artístico.

- Pessoa física filiada: argumenta que é preciso analisar caso a caso, levando-se em conta as especificidades de cada organização. Afirma que as organizações $C$ e $D$ são reconhecidas e que têm projetos aprovados nos conselhos estaduais e nacional dos Direitos da Criança e do Adolescente. Sugere que o pedido da organização A e B sejam primeiro submetidos às instâncias estaduais que atuam na área de trabalho infantil.

- Pessoa física filiada: ressalta que a filiação ao FNPETI é importante, pois significa a legitimidade do fórum.

Ao final, os presentes chegaram a um consenso sem precisar de votação, prática essa não inserida na cultura do FNPETI, que reafirma em todas as assembleias a necessidade de acordos para se evitar o voto. 0 resultado foi: organização $C$ e $D$ aprovadas por aclamação e pedidos das organizações A e B remetidos para instâncias estaduais da área de trabalho infantil, para possível aprovação prévia nos seus estados de origem e, só depois, nova discussão sobre sua filiação em âmbito nacional.

Essa unidade de análise sobre as filiações nos indica o quanto a mediação e a produção discursiva são estruturantes do FNPETI. As argumentações foram de muitas naturezas e revelaram os posicionamentos e os lugares de fala das organizações associadas. Também demonstraram interesses e poderes contrapostos que afetaram a produção e a regulação dos discursos, como definido pela institucionalidade. 
A representante do fórum estadual, por exemplo, argumenta que as filiações ao fórum nacional sejam decididas, antes, pelas instâncias estaduais, levando-nos a inferir sobre sua busca em visibilizar e legitimar o papel dos fóruns nos estados. Já a fala do representante do segmento empresarial, uma das que durou mais tempo e teve muitos pedidos de apartes, evidencia a busca por critérios técnicos, tentando tirar de foco a questão do financiador da organização A, uma empresa de agricultura, de cujo ramo a organização do segmento empregador faz a representação nacional em outra instância representativa (neste caso sindical patronal).

Os argumentos para negar a filiação das duas organizações tiveram coerência com um princípio institucional fundamental para o fórum - não ter ligação com trabalho infantil, seja na ação direta seja no financiamento -, neste caso, dos ramos fumageiro e de entretenimento.

Isso nos remete ao que Martín-Barbero fala sobre a busca de alguns movimentos em construir outras institucionalidades, afastando-se dos modelos clássicos para atender a interesses e lógicas privados. 0 que estava em jogo na discussão não eram só as organizações, mas todo o sentido social e político que elas carregavam e representavam em relação ao tema do trabalho infantil, explicitado pelas suas escolhas de financiamento. Tal fato nos aponta uma cultura organizacional e um posicionamento político do fórum, que constituem sua forma de institucionalidade.

Para analisarmos a articulação entre comunicação, cultura e política como trama das mediações do FNEPTI, recorremos ao seu documento institucional contendo definição, objetivos e estrutura, de maneira a identificarmos elementos constitutivos dessa organização que nos permitissem fazer uma leitura a partir dos postulados das mediações.

Em relação à sua definição, o fórum se atribui os seguintes termos: estratégia da sociedade brasileira de articulação e aglutinação de atores sociais institucionais, envolvidos com políticas e programas de prevenção e erradicação do trabalho infantil no Brasil; instância autônoma de controle social; espaço democrático, não institucionalizado, de discussão de propostas, estratégias e formação de consensos entre sociedade civil e governo acerca da temática do trabalho infantil.

Analisamos, por tais definições, que o fórum se situa como (i) ator social específico de um campo político (da infância e ligado ao enfrentamento do trabalho infantil); (ii) não partidário, explicitado por ser instância autônoma e não institucionalizada; (iii) com diversas funções que podem se localizar no campo comunicacional: articulação/aglutinação, discussão e formação de consensos; e (iv) envolvendo sociedade civil e governo.

Com base nessa descrição, podemos fazer uma leitura sobre como o comunicacional, o cultural e o político estão presentes nessa organização. Como um novo ator social, na concepção de Martín-Barbero, percebemos o quanto a comunicação é constitutiva do fórum, haja vista que ele tem como definição e funções dialogar, consensuar e articular atores sobre algo não material, mas sim ligado ao campo simbólico - enfrentar o trabalho infantil. Portanto, imerso no universo comunicacional.

Do ponto de vista cultural aqui abordado, definimos o FNPETI inserido na cultura de direitos humanos de crianças e adolescentes. Determinada parcela da sociedade brasileira vinha reivindicando, sobretudo a partir dos anos 1980, a afirmação dos direitos humanos, emergindo uma nova noção de cidadania (Matos, 2009; Gohn, 2005), que foi central para os movimentos e organizações da infância.

Dessa forma, foi-se buscando criar (sempre e continuamente, ao se considerar a cultura viva e dinâmica) uma cultura de direitos da infância e da adolescência e demarcando-se campos de atuação capazes de enfrentar as violências e violações que ameaçavam e ameaçam tais direitos. O FNPETI, assim, é expressão dessa cultura, específica de um campo de atuação e de um tema, o trabalho infantil. 
0 político é expresso, nessa organização, por sua própria natureza e seu formato: o FNPETI é uma maneira de se fazer política e de agir politicamente dentro das novas configurações definidas por Martín-Barbero. Ao se debruçar sobre uma política pública (enfrentamento ao trabalho infantil), os membros do fórum o fazem a partir de relações e interações nas quais disputam sentidos e também poder - de conceituar e de decidir os caminhos necessários para a ação.

Definimos que o FNPETI é mediado por uma cultura política e organizacional própria (interna), tangenciada pela cultura política e organizacional de cada uma das instituições que o compõem, bem como medeia, culturalmente, o tema dos direitos das crianças e dos adolescentes na esfera pública. Também entendemos que ele é um mediador sociocultural que faz a ponte/o intercâmbio entre atores sociais do campo da infância e da adolescência com o governo e a sociedade civil, assim como do tema dos direitos infantojuvenis, sobretudo do direito ao não trabalho.

Ao analisarmos a definição e os objetivos institucionais do FNPETI, constantes no seu documento-base, observamos o quanto a organização está inserida na comunicação pública. Mainiere (2016) argumenta que a comunicação pública é espaço de interlocução entre agentes sociais e políticos no debate das questões de interesse público, o que está na própria natureza do fórum. Ele se conforma como um espaço de articulação e diálogo entre atores estratégicos do campo da infância em prol de um interesse público: a defesa dos direitos da infância e da adolescência.

O conceito de participação, defendido por Matos (2011), também está presente na comunicação do FNPETI para caracterizála como pública. A organização é um espaço de densa participação entre campos sociais diversificados que, como vimos, produz e regula discursos públicos acerca de uma política pública específica, contra o trabalho infantil.

$\mathrm{Na}$ análise do documento institucional do fórum, encontramos alguns condicionantes formulados por Duarte (2009) como necessários para se caracterizar a comunicação pública: (i) identificar demandas sociais (a organização realiza estudos e pesquisas para entender o contexto do trabalho infantil no Brasil e sua relação com o cenário mundial); (ii) qualificar as políticas públicas (a organização tem ações de formulação, monitoramento e avaliação da política pública sobre trabalho infantil); (iii) garantir a participação de segmentos organizados da sociedade civil (a organização congrega atores de diversos campos e promove ações de mobilização para buscar ampliar a participação).

\section{CONSIDERAÇÕES FINAIS}

O objetivo deste trabalho foi compreender de que forma o FNPETI se estrutura como uma organização social de mediação que produz comunicação pública. Trata-se de uma organização do campo da infância e adolescência relativamente nova, criada em 1994, portanto, logo após a promulgação da Constituição Federal (1988) e do ECA - Estatuto da Criança e do Adolescente (1990), e que, de forma pioneira, começou a tratar de um tema até então invisibilizado na sociedade brasileira, o trabalho infantil.

Seu formato híbrido, congregando atores de campos tão distintos, como sociedade civil e governo, empregadores e trabalhadores, e sua natureza de articulação em prol do interesse público dos direitos infantojuvenis, o configuram como organização de mediação, que tem na comunicação pública sua principal referência.

A articulação dos atores se dá em meio a um cenário no qual seus interesses e poderes são bastante distintos e assimétricos, indicando-nos como opera a mediação da institucionalidade de Martín-Barbero (2008). A produção e a regulação de discursos é tarefa que reivindica intensas e constantes negociações a fim de pactuar, sempre que possível, o que pode ser exposto na esfera pública. 
Este estudo nos permitiu fazer uma leitura de uma organização social a partir das abordagens dos estudos de recepção, em particular dos postulados de Martín-Barbero, bem como da comunicação pública. Isso agregou outro olhar sobre a organização estudada, o FNPETI, permitindo-nos entendê-la com base na associação entre comunicação, cultura e política, o que demonstra ser pertinente, sobretudo em uma organização da natureza do fórum, de articulação de atores em torno de uma política pública, o enfrentamento do trabalho infantil.

Os resultados indicaram a pertinência dessa construção teórica para o campo organizacional e apontaram a necessidade de novas investigações, capazes de aprofundar a análise, bem como permitir novos desdobramentos. Um deles seria analisar, do ponto de vista da comunicação pública, algumas ações realizadas pelo FNPETI, constantes no seu documento institucional, como as ações de mobilização e de incidência política. Essa foi uma etapa analítica que se mostrou frutífera e que apontou possibilidades de seguimento da pesquisa.

\section{REFERÊNCIAS}

BARDIN, Laurence. Análise de conteúdo. São Paulo: Edições 70, 2011.

DUARTE, Jorge (Org.). Comunicação pública: estado, mercado, sociedade e interesse público. 2. ed. São Paulo: Atlas, 2009.

GOHN, Maria da Glória. O protagonismo da sociedade civil: movimentos sociais, ONGs e redes solidárias. São Paulo: Cortez, 2005.

LÓPEZ, Juan Jaramillo. Advocacy: uma estratégia de comunicação pública. In: KUNSCH, Margarida M. Krphling (Org.). Comunicação pública, sociedade e cidadania. São Caetano do Sul, SP: Difusão, 2011.

MAINIERE, Tiago. Um peso, duas medidas. desvelando a comunicação pública na sociedade midiatizada. Goiânia: Gráfica UFG, 2016.

MARTÍN-BARBERO, Jesús. Dos meios às mediações. 5. ed. Rio de Janeiro: EdUERJ, 2008.

. América Latina e os anos recentes: o estudo da recepção em comunicação social. In: SOUSA, Mauro Wilton. Sujeito, 0 lado oculto do receptor. São Paulo: Brasiliense, 1995.

. As formas mestiças da mídia. [Entrevista a Mariluce Moura]. Pesquisa Fapesp, n. 163, set. 2009.

MATOS, Marlise. Cidadania porque, quando, para quê e para quem? Desafios contemporâneos ao estado e à democracia inclusiva. In: MATOS, Marlise et al. (Orgs.). Cidadania e a luta por direitos humanos, sociais, econômicos, culturais e ambientais. Belo Horizonte: UFMG, 2009.

MATOS, Heloiza. A comunicação pública na perspectiva da teoria do reconhecimento. In: KUNSCH, Margarida M. Krohling (Org.). Comunicação pública, sociedade e cidadania. São Caetano do Sul, SP: Difusão, 2011.

PNAD. Pesquisa nacional por amostra de domicílios. Rio de Janeiro: IBGE, 2014.

SCHERER-WARREN, Ilse. Das mobilizações às redes de movimentos sociais. Soc. estado [online], Brasília, v. 21, n. 1, p. 109130, jan./abr. 2006.

Texto recebido em 30.03.2017 e aprovado em 27.06.2017. 